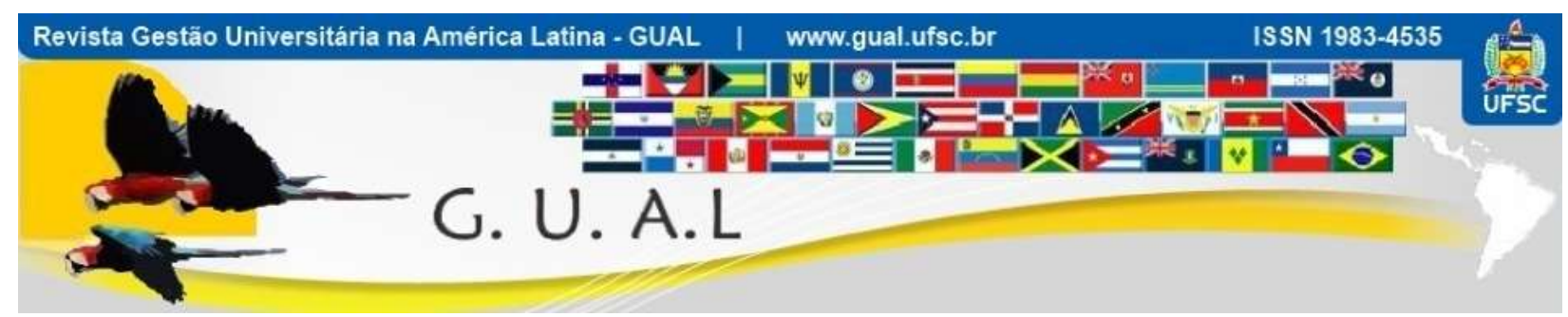

DOI: https://doi.org/10.5007/1983-4535.2021.e73091

\title{
ESTILOS GERENCIAIS DOS COORDENADORES DE CURSOS DE GRADUAÇÃO DE UMA INSTITUIÇÃO DE ENSINO SUPERIOR
}

\section{MANAGEMENT STYLES OF THE UNDERGRADUATE COURSE COORDINATORS OF A HIGHER EDUCATION INSTITUTION}

\begin{abstract}
Evanilde Gollo Cordazzo, Mestre
https://orcid.org/0000-0002-5849-4897 evanilde@unochapeco.edu.br Universidade Comunitária da Região de Chapecó | Programa de Pós-Graduação em Ciências Contábeis e Administração Chapecó| Santa Catarina | Brasil

Rodney Wernke, Doutor https://orcid.org/0000-0002-5473-9973 rodneywernke1@hotmail.com São Ludgero | Santa Catarina | Brasil

Antonio Zanin, Doutor http://orcid.org/0000-0001-5163-5004 zanin.antonio@ufms.br Universidade Federal de Mato Grosso do Sul / Ciências Contábeis Nova Andradina| Mato Grosso do Sul | Brasil
\end{abstract}

Recebido em 19/abril/2020

Aprovado em 09/novembro/2020

Publicado em 01/janeiro/2021

Sistema de Avaliação: Double Blind Review 


\title{
ESTILOS GERENCIAIS DOS COORDENADORES DE CURSOS DE GRADUAÇÃO DE UMA \\ INSTITUIÇÃO DE ENSINO SUPERIOR \\ DOI: https://doi.org/10.5007/1983-4535.2021.e73091
}

\section{RESUMO}

O estudo objetivou identificar os estilos gerenciais dos coordenadores de curso de graduação de uma instituição de ensino superior comunitária sediada em Santa Catarina. Para tal, realizou-se pesquisa descritiva, com abordagem quantitativa. Os dados foram apurados por meio de levantamento (survey) baseado em questionário respondido por 20 coordenadores de cursos da universidade pesquisada, cujos dados foram analisados por meio de estatística descritiva. Os principais achados da pesquisa revelam coordenadores com formação adequada para o exercício de tal função, além de que grande parte dos respondentes possui experiência anterior na área de gestão. Quanto às principais funções evidenciadas pelos respondentes, estas referem-se à organização $(75 \%)$, ao planejamento $(65 \%)$, à liderança $(55 \%)$ e à de mediador $(50 \%)$. Em relação a organização das atividades na instituição, identificou-se que a maioria (75\%) dos respondentes dedica-se mais expressiva na realização das atividades rotineiras, em relação ao processo de tomada de decisão sobre o gerenciamento do curso, doze destacaram que as decisões gerenciais são tomadas na maioria das vezes juntamente com os gestores hierarquicamente superiores. Os resultados indicam, ainda, coordenadores mais voltados à gestão dos próprios cursos, mas que não deixam de pensar na instituição como um todo. Também foi possível constatar que os coordenadores mostraram-se preocupados com a qualidade dos cursos, mantendo bom nível de comunicação com seus pares, bem como com os demais cursos de graduação da instituição.

Palavras-chave: Estilos Gerenciais. Coordenadores de Curso. Instituição de Ensino Superior.

\begin{abstract}
The aim of this study was to identify the managerial styles of undergraduate course coordinators of a community higher education institution in Santa Catarina. To reach this goal, a descriptive research with a quantitative approach it was carried out. The data were obtained by means of a survey based on a questionnaire, which was answered by 20 course coordinators of the researched university, whose data were analyzed through descriptive statistics. The main findings of the research reveal coordinators with adequate formation to perform this job, in addition to the fact that most of the respondents have previous experience in the area of management. Regarding the main jobs highlighted by the respondents, these refer to the organization (75\%), planning (65\%), leadership (55\%) and mediator $(50 \%)$. Regarding the organization of the activities in the institution, it was identified that the majority $(75 \%)$ of the respondents spend most of their time in carrying out routine activities, in relation to the decision-making process on the management of the course, twelve coordinators pointed out that the managerial decisions are most often taken together with the hierarchically superior managers. The results also indicate coordinators more focused on the management of their courses, who do not forget to think about the institution as a whole though. It was also possible to verify that the coordinators were concerned with the quality of the courses, maintaining a good level of communication with their peers, as well as with the other undergraduate courses of the institution.
\end{abstract}

Keywords: Management Styles. Undergraduate Course Coordinators. Higher Education Institution. 


\section{ESTILOS GERENCIAIS DOS COORDENADORES DE CURSOS DE GRADUAÇÃO DE UMA \\ INSTITUIÇÃO DE ENSINO SUPERIOR \\ DOI: https://doi.org/10.5007/1983-4535.2021.e73091}

\section{INTRODUÇÃO}

As organizações estão sujeitas às pressões ambientais e o mercado cada vez mais concorrido requer posturas agressivas das organizações, aliadas à necessidade de um processo de gestão para a tomada de decisões mais ágil e eficiente (EBERLE; COLAUTO, 2015). Provavelmente este cenário também é vivenciado pelas instituições de ensino superior, onde determinados fatores podem influenciar mais que em outros tipos de empreendimentos.

Nesse sentido, a gestão de uma Instituição de Ensino Superior (IES) é bem complexa em virtude de sua estrutura, organização e objetivos específicos. Além disso, essas entidades enfrentam diversos desafios na atualidade, destacando-se o acirramento da concorrência e o aumento de exigências legais no âmbito educacional. Então, melhorar a eficácia gerencial torna-se uma necessidade para que as IES possam enfrentar os desafios atuais, demandando ainda mais habilidade de seus gestores (SANTOS; BRONNEMANN, 2013: ZANIN et al., 2015).

Por outro lado, a legislação brasileira, Art. $3^{\circ}$ do Decreto 94.664/1987, prevê que a gestão das IES deve ser desempenhada por professor, juntamente com as atividades de ensino, pesquisa e extensão. Assim, ao assumir um cargo de gestão este passa a atuar como professorgestor, os quais possuem funções e papéis característicos no mundo acadêmico, pois antes de serem gestores estes são professores do ensino superior (BARBOSA; MENDONÇA, 2016).

Nesse rumo, Cunha (1999) assevera que se espera cada vez mais que o professorgestor desempenhe uma gama de atividades concomitantes ao ensino, tais como as de cunho administrativo, de líder educacional, de representante da instituição, de coordenação etc. Com isso, de acordo com Santos e Bronnemann (2013), a eficácia na execução das atividades de gestão nem sempre ocorre, pois nas IES os gestores normalmente são docentes que assumem seus cargos sem conhecimento gerencial, de liderança e de gestão de pessoas, devido à falta de experiência de gestão, o que pode acarretar diferentes dificuldades. Entendimento corroborado por Silva e Costa (2014), que aduzem que a formação dos professores de ensino superior no Brasil é mais voltada ao perfil de pesquisador e especialista em seus temas de estudo.

Diante do exposto este estudo se propõe a responder a seguinte questão de pesquisa: quais os estilos gerenciais dos coordenadores de curso de graduação de uma instituição de ensino superior? Para tanto, a pesquisa tem como objetivo identificar os estilos gerenciais dos 


\section{ESTILOS GERENCIAIS DOS COORDENADORES DE CURSOS DE GRADUAÇÃO DE UMA \\ INSTITUIÇÃO DE ENSINO SUPERIOR \\ DOI: https://doi.org/10.5007/1983-4535.2021.e73091}

coordenadores de curso de graduação de uma instituição de ensino superior comunitária sediada em Santa Catarina.

Destarte, busca-se com esse trabalho preencher uma lacuna ainda existente no âmbito das pesquisas empíricas e relacionada aos estilos gerenciais dos coordenadores de curso de graduação. Nessa direção, tendo em vista que uma IES deve ter como premissa a qualidade do ensino ofertado, as estratégias de gestão e as ações dos gestores devem alinhar-se a este foco, cabendo aos coordenadores de curso um papel fundamental nesse processo (BRITO, 2008). Sobre isso, Silveira-Martins et al. (2017) destacam que o coordenador responde pela gestão do curso perante outros docentes, discentes, colegiados etc. e assume o papel de conduzir as ações de planejamento do curso. No entanto, devido à falta de experiência e conhecimento na seara administrativa, os coordenadores podem ter dificuldade para gerenciar os cursos. Por isso, Barbosa e Mendonça (2016) destacam que cada vez mais exige-se profissionais capacitados e preparados para ocupar cargos de gestão no âmbito universitário.

\section{FUNÇÕES E PAPÉIS DOS GESTORES EDUCACIONAIS}

Diversos papéis, funções e responsabilidades podem ser atribuídos aos gestores educacionais. Sobre isso, Soares (2013) registra que integra o papel do gestor universitário unir os interesses dos discentes ao projeto pedagógico, observando a necessidade do mercado em relação aos egressos de sua instituição.

Bayarystanova, Arenova e Nurmuhametova (2014) pugnam que o principal objetivo deve ser o de coordenar as atividades dos demais envolvidos nos processos administrativo e pedagógico da instituição, a fim de obter resultados que atendam as demandas institucionais, dos estudantes e da sociedade como um todo. Argumentam, também, que se deve observar a peculiaridade da gestão educacional ter que integrar a gestão pedagógica e a institucional; dessa forma, todos os objetivos deverão ser alinhados à realização do objetivo de formar alunos com qualidade.

Além disso, o gestor deve desenvolver algumas qualidades e habilidades profissionais relevantes para o processo de gestão. Entre as qualidades gerais de personalidade devem estar a criatividade e a inteligência, enquanto que no âmbito das qualidades profissionais específicas deve constar o espírito empreendedor. Destarte, como habilidades profissionais necessárias enquadram-se a competitividade e a habilidade de liderança comunicativa, mas ainda são requeridas qualidades individuais de personalidade, como a adaptabilidade social, a 


\section{ESTILOS GERENCIAIS DOS COORDENADORES DE CURSOS DE GRADUAÇÃO DE UMA \\ INSTITUIÇÃO DE ENSINO SUPERIOR \\ DOI: https://doi.org/10.5007/1983-4535.2021.e73091}

estabilidade emocional e a velocidade de reações psicológicas (BAYARYSTANOVA; ARENOVA; NURMUHAMETOVA, 2014).

Barbosa e Mendonça (2016) caracterizam o papel do gestor universitário pelas múltiplas tarefas desenvolvidas com o intuito de fomentar e incentivar o desenvolvimento organizacional concomitante às atividades de ensino, pesquisa e extensão, reafirmando a necessidade de que esses profissionais devem desenvolver competências gerenciais, além das competências técnicas, porque há significativas diferenças entre as funções. Esse entendimento é compartilhado por Miranda (2010) ao ressaltar que as competências gerenciais possibilitam ao gestor alinhar o conhecimento técnico ao administrativo, visto que o aprendizado dos docentes em relação às atividades gerenciais ocorre na prática (no dia a dia) com a execução das atividades.

Diante do exposto é possível perceber o coordenador de curso de graduação como um importante gestor na condução do processo de qualificação do ensino ofertado, uma vez que é responsável por acompanhar o desenvolvimento do estudante visando a formação de profissionais qualificados (COSTA, 2016). Contudo, o coordenador de curso de graduação é um docente da organização que pode assumir a função por indicação ou eleição de seus pares, de acordo com as normas institucionais. Ao assumir a coordenação este não vai deixar de ser professor, nas terá uma nova identidade: a de gerente. Alguns assumirão a função sem experiência em cargos similares e estes apresentarão, de início, comportamento de docentes preocupados apenas com a sala de aula. Do contrário, os que já tiveram experiências anteriores em cargos gerenciais apresentarão comportamentos característicos de gerentes, além dos de docência (MARCON, 2011).

Acerca disso, ao justificar a inexistência de perfeição humana, Franco (2002) pugna que não se pode idealizar uma pessoa perfeita para exercer a função de coordenador de um curso de graduação. Contudo, espera-se que este seja uma pessoa ética, com ideias claras e expectativas audaciosas, além de bom relacionamento com professores e alunos, mas que também tenha iniciativa e discernimento para desvincular os que não merecem estar vinculados ao curso. Entretanto, ao assumir a função de coordenador o docente terá conhecimento prévio das responsabilidades assumidas, visto que a organização já tem a função com atribuições definidas em documentos normativos. Com isso, o coordenador tende a executar as tarefas originadas por demandas imediatas, visando à produtividade do fazer. Além disso, é fundamental para o gestor conhecer o papel ou a função do seu cargo, pois isso 


\section{ESTILOS GERENCIAIS DOS COORDENADORES DE CURSOS DE GRADUAÇÃO DE UMA \\ INSTITUIÇÃO DE ENSINO SUPERIOR \\ DOI: https://doi.org/10.5007/1983-4535.2021.e73091}

possibilitará um melhor planejamento das atividades, conhecer e estabelecer relações profissionais internas e externas à organização, bem como avaliar os resultados das relações estabelecidas. Adicionalmente, diante do cenário competitivo em que as IES estão inseridas, não é permitido improvisações ou dúvidas em relação às atividades a serem desenvolvidas. Por isso, é essencial que as decisões sejam fundamentadas no planejamento institucional realizado com foco na atividade-fim, elaborado de acordo com as necessidades da instituição e alinhado às necessidades da sociedade (MARCON, 2011)

\section{METODOLOGIA}

Este estudo caracteriza-se como "descritivo", uma vez que o objetivo principal desta modalidade de pesquisa consiste em descrever as características de determinada população, podendo ser utilizado com a finalidade de identificar relações entre variáveis (GIL, 2010). Quanto à abordagem, classifica-se como quantitativa, pois utiliza-se de instrumentos estatísticos para a coleta e tratamento dos dados (RAUPP; BEUREN, 2003).

Em relação aos procedimentos, classifica-se como levantamento (ROESCH, 2006) porque visa obter informações sobre uma determinada população. Neste caso, o levantamento foi efetuado a partir de questionário específico, fundamentado no estudo de Oliveira et al. (2015), mas com ampliação no número de questões e adequações ao contexto universitário.

A primeira parte do questionário foi composta por dezoito perguntas relacionadas ao perfil do respondente, abrangendo questões fechadas de múltipla escolha e abertas. A segunda parte envolveu perguntas acerca do estilo gerencial do respondente, a qual foi subdividida em cinco seções. A primeira seção foi composta por sete questões e buscava conhecer sobre o processo de comunicação na instituição universitária pesquisada. A segunda, solicitava aos respondentes indicar as três principais funções desempenhadas na entidade, a partir de uma lista de onze funções pré-definidas. A terceira seção, composta por oito questões fechadas de múltipla escolha, inquiriu sobre a organização das atividades na IES pesquisada.

As duas últimas seções indagavam sobre a abordagem do processo e dos papéis, sendo compostas por 15 e 21 questões, respectivamente, com formato de múltipla escolha. Para essas duas partes utilizou-se uma escala do tipo Likert de sete pontos, onde os extremos representavam "muito raramente" (1) e "muito frequentemente" (7).

A título de pré-teste, o questionário foi enviado a uma coordenadora de curso com experiência na gestão do curso com o objetivo de validar as adaptações efetuadas a partir do 
estudo utilizado como base (OLIVEIRA et al., 2015), que sugeriu alterações na redação de algumas questões. Posteriormente, o questionário foi enviado aos 43 coordenadores e coordenadores adjuntos de cursos da instituição por meio de correio eletrônico, acompanhado de texto explicativo sobre o objetivo da pesquisa, finalidade dos dados e assegurando a confidencialidade das respostas.

Para esse envio, inicialmente foi encaminhado um e-mail pela Diretoria de Desenvolvimento Humano da instituição. Tal mensagem continha o link eletrônico para acesso ao questionário, que foi elaborado e disponibilizado via ferramenta Google Docs. Na sequência, para reforçar foi enviado novamente, pelos próprios pesquisadores, por e-mail aos possíveis respondentes nos meses de junho e julho de 2017. Com isso, foram obtidas vinte respostas, representando $46,5 \%$ do número total de respondentes que seria possível se abrangidos todos os cursos da universidade em tela.

É pertinente citar que a escolha da instituição universitária para realizar o estudo teve o caráter de intencional e se deu pelo critério de acessibilidade dos respondentes. Portanto, as conclusões limitam-se a essa realidade empresarial, sem permitir extrapolações para outros contextos. Convém salientar, ainda, que a referida entidade está sediada no estado de Santa Catarina e oferta cursos de graduação e de tecnólogo (presencial e a distância), especializações, mestrados e doutorados, classificados em quatro áreas do conhecimento. Contudo, por solicitação dos gestores, esta não será identificada em termos de sua razão social ou nome de fantasia.

Quanto à análise dos dados, foi empregada a estatística descritiva para obter os percentuais das respostas em cada um dos aspectos mais relevantes, como destacado nas próximas seções.

\section{APRESENTAÇÃO E ANÁLISE DOS DADOS}

As respostas coligidas por intermédio dos questionários devolvidos pelos respondentes permitiram evidenciar os aspectos salientados na sequência.

\subsection{PERFIL DO RESPONDENTE E DA INSTITUIÇÃO}

Acerca do perfil dos vinte respondentes foram apuradas as seguintes peculiaridades, conforme evidenciadas no Quadro 1. 


\section{ESTILOS GERENCIAIS DOS COORDENADORES DE CURSOS DE GRADUAÇÃO DE UMA \\ INSTITUIÇÃO DE ENSINO SUPERIOR \\ DOI: https://doi.org/10.5007/1983-4535.2021.e73091}

Quadro 1 Perfil do respondente

\begin{tabular}{|c|c|}
\hline Questão & Perfil apurado \\
\hline Idade & $\begin{array}{l}\text { A maioria (60\%) dos coordenadores possui entre } 36 \text { e } 45 \text { anos, enquanto } \\
\text { que } 25 \% \text { (cinco participantes) possuem entre } 26 \text { e } 35 \text { anos e apenas três } \\
(15 \%) \text { possuem entre } 46 \text { e } 55 \text { anos. }\end{array}$ \\
\hline Gênero & $\begin{array}{l}\text { Constatou-se a predominância das mulheres à frente da coordenação dos } \\
\text { cursos, pois doze }(60 \%) \text { são do gênero feminino e oito coordenadores } \\
(40 \%) \text { são do gênero masculino }\end{array}$ \\
\hline $\begin{array}{l}\text { Vínculo com a } \\
\text { instituição }\end{array}$ & $\begin{array}{l}\text { Dezessete ( } 85 \% \text { ) são coordenadores de curso e apenas } 15 \% \text { (três) são } \\
\text { coordenadores adjuntos. }\end{array}$ \\
\hline $\begin{array}{l}\text { Experiência } \\
\text { profissional anterior } \\
\text { (em outra empresa ou } \\
\text { instituição de ensino) }\end{array}$ & $\begin{array}{l}\text { Apurou-se que } 14 \text { dos respondentes ( } 70 \% \text { ) afirmaram ter tido experiências } \\
\text { anteriores. }\end{array}$ \\
\hline $\begin{array}{l}\text { Tempo de atuação na } \\
\text { área de gestão }\end{array}$ & $\begin{array}{l}\text { Dois respondentes ( } 10 \%) \text { revelaram atuar há "menos de } 2 \text { anos"; quatro } \\
(20 \%) \text { evidenciaram que atuam nessa atividade por período "entre } 2 \text { e } 5 \\
\text { anos"; onze respondentes ( } 55 \%) \text { atuam na área de gestão entre " } 5,1 \text { e } 10 \\
\text { anos" e apenas três coordenadores ( } 15 \%) \text { atuam entre " } 10,1 \text { e } 15 \text { anos". }\end{array}$ \\
\hline $\begin{array}{l}\text { Tempo de atuação na } \\
\text { instituição }\end{array}$ & $\begin{array}{l}\text { A maior concentração de respondentes ficou na faixa de " } 5,1 \text { a } 10 \text { anos" } \\
\text { com } 35 \% \text { (sete respondentes), sendo seguida pelo estrato de "10,1 a } 15 \\
\text { anos" com } 25 \% \text { (cinco participantes). Quatro respondentes ( } 20 \%) \\
\text { informaram estar na instituição há menos de } 5 \text { anos; dois respondentes } \\
(10 \%) \text { informaram atuar na IES entre " } 15,1 \text { e } 20 \text { anos" e outros dois } \\
(10 \%) \text { estão trabalhando há "mais de } 20 \text { anos". }\end{array}$ \\
\hline Nível de escolaridade & $\begin{array}{l}\text { Apenas dois respondentes }(10 \%) \text { informaram serem especialistas, } \\
\text { enquanto que quinze }(75 \%) \text { são mestres e três }(15 \%) \text { são doutores. }\end{array}$ \\
\hline $\begin{array}{l}\text { Número de alunos por } \\
\text { curso }\end{array}$ & $\begin{array}{l}\text { Cinco cursos contavam com até } 100 \text { alunos regularmente matriculados, } \\
\text { sete cursos tinham entre } 101 \text { e } 200 \text { alunos, dois possuíam entre } 201 \text { e } 300 \\
\text { alunos, três cursos situavam-se na faixa de } 301 \text { a } 400 \text { alunos matriculados } \\
\text { e os três maiores cursos contavam com aproximadamente } 550,570 \text { e } \\
1.200 \text { alunos regulares. }\end{array}$ \\
\hline $\begin{array}{l}\text { Participação em } \\
\text { grupos de pesquisa }\end{array}$ & $\begin{array}{l}\text { Dos } 20 \text { respondentes, } 70 \% \text { (14) disseram que participam desse tipo de } \\
\text { grupo, enquanto que } 30 \% \text { (6) não estavam participando de qualquer } \\
\text { projeto de pesquisa. }\end{array}$ \\
\hline $\begin{array}{l}\text { Participação em cursos } \\
\text { de capacitação } \\
\text { relacionados à gestão }\end{array}$ & $\begin{array}{l}\text { Quatro dos respondentes (20\%) disseram não participar de capacitações e } \\
\text { dezesseis ( } 80 \%) \text { citaram participar destes, treze citaram que participam de } \\
\text { "ao menos uma capacitação por ano"; três afirmaram participar de " } 2 \text { a } 5 \\
\text { capacitações por ano" e um respondente indicou participar em "mais de } 5 \\
\text { capacitações por ano". Observa-se que um dos respondentes alegou, } \\
\text { anteriormente, não participar de capacitações relacionadas à gestão e, na } \\
\text { sequência, informou participar de ao menos uma capacitação por ano. }\end{array}$ \\
\hline
\end{tabular}

Fonte: Dados da pesquisa.

De modo geral, os dados colhidos revelam um perfil de gestores relativamente jovens, visto que a maioria (85\%) dos coordenadores participantes da pesquisa tem menos de 45 anos. Os resultados indicam, ainda, que para alguns dos coordenadores esta é a primeira experiência na área de gestão, pois 30\% (seis) dos respondentes informaram experiência anterior nessa área de até 5 anos. Outra constatação refere-se ao alinhamento dos coordenadores ao conceito 
e práticas de universidade, especialmente devido ao expressivo percentual de respondentes com envolvimento em pesquisa. Ainda, verifica-se que grande parte dos coordenadores tem titulação adequada para tal função, o que corrobora o entendimento de Barbosa e Mendonça (2016) sobre a crescente busca pela qualificação profissional dos gestores desse tipo de instituição.

\subsection{ESTILO GERENCIAL DO RESPONDENTE}

A segunda parte do estudo foi composta por questões relacionadas ao estilo gerencial do respondente, ao processo de comunicação e planejamento estratégico, funções exercidas, organização das atividades na instituição, abordagem do processo e abordagem dos papéis.

Em relação ao processo de comunicação, a primeira e a segunda questões indagavam acerca da comunicação entre a reitoria e os cursos e entre e direção de área e os cursos, cujos resultados estão evidenciados na Tabela 1 .

Tabela 1: Processo de comunicação (como ocorre a comunicação?)

\begin{tabular}{l|c|c|c|c}
\hline \multirow{2}{*}{ Itens } & \multicolumn{2}{|c|}{ Reitoria } & \multicolumn{2}{c}{ Direção de Área } \\
\cline { 2 - 5 } & $\mathbf{N}^{\mathbf{0}}$ & $\mathbf{\%}$ & $\mathbf{N}^{\mathbf{0}}$ & $\mathbf{\%}$ \\
\hline Somente de modo verbal (conversas/reuniões) & 1 & 5 & 0 & 0 \\
A maioria das comunicações de modo verbal, mas & 4 & 20 & 16 & 80 \\
com algumas por escrito (papel, e-mail, Skype etc.) & 4 & & & 20 \\
A maioria das comunicações por escrito (papel, e- & 15 & 75 & 4 & - \\
mail, Skype etc.) & - & - & - & - \\
Somente por escrito (papel, e-mail, Skype etc.) & - & &
\end{tabular}

Fonte: dados da pesquisa.

A respeito da comunicação entre reitoria e os cursos constatou-se que quinze dos respondentes (o que equivale a 75\%) consideram que a maioria das comunicações ocorre por escrito. Apenas quatro (20\%) consideraram que a maioria das comunicações ocorre de modo verbal, mas com algumas por escrito e só um respondente citou que acontece apenas verbalmente. Em relação à comunicação entre a direção de área e os cursos, observou-se que dezesseis respondentes $(80 \%)$ concordam que a comunicação ocorre na maioria das vezes de modo verbal (mas, com algumas por escrito) e apenas quatro (20\%) indicaram que acontece na maioria das vezes por escrito.

A terceira questão relacionada ao processo de comunicação perguntava sobre quais ferramentas informatizadas a instituição pesquisada utiliza para registro de informações e 


\section{ESTILOS GERENCIAIS DOS COORDENADORES DE CURSOS DE GRADUAÇÃO DE UMA \\ INSTITUIÇÃO DE ENSINO SUPERIOR \\ DOI: https://doi.org/10.5007/1983-4535.2021.e73091}

fluxos de mensagens, sendo que os respondentes poderiam indicar mais de uma opção e incluir outras ferramentas na resposta (questão aberta).

Ainda relacionado à comunicação, a quarta pergunta questionava se para tomar as decisões importantes relativas à instituição o respondente consultava outras pessoas. Todos os respondentes manifestaram consultar outros gestores, quinze $(75 \%)$ citaram consultar apenas os gestores responsáveis pelas diretorias/setores envolvidos. Isso pode indicar que os gestores possuem certa autonomia e poder de decisão dentro da instituição em tela.

Ao serem questionados sobre se a instituição elabora planejamento estratégico, apenas um respondente selecionou a opção "não", enquanto que os outros dezenove respondentes (95\%) citaram "sim". Ainda em relação ao planejamento estratégico foi indagado quais informações são priorizadas, onde os respondentes poderiam indicar mais de uma opção. Dos dezenove respondentes, dezessete $(89,5 \%)$ acharam que são priorizados os objetivos e metas, sete $(36,8 \%)$ sugerem que é priorizado o horizonte de planejamento (tempo de duração do plano estratégico), oito $(42,1 \%)$ indicaram os fatores internos e externos que podem afetar a instituição e três $(15,8 \%)$ mencionaram a avaliação periódica da evolução do plano estratégico e a divulgação do planejamento estratégico aos funcionários.

A sétima e última questão relacionada ao processo de comunicação inquiriu sobre a forma de realização do planejamento estratégico. Um dos respondentes (5\%) salientou não ser realizado planejamento, nove (45\%) afirmaram que o processo não é sistemático (é realizado somente às vezes) e dez (50\%) alegaram que o processo é sistemático, ou seja, contínuo. Os dados indicam falhas no processo de comunicação, especialmente em relação ao planejamento estratégico, visto haver discordância (ou desconhecimento) entre os respondentes acerca das prioridades e do processo de elaboração deste.

Outro quesito abordado na pesquisa indagava a respeito das funções do respondente na instituição. Para essa finalidade foram apresentadas onze opções de acordo com as funções do administrador aventadas por Oliveira et al. (2015). Então, foi solicitado ao respondente que indicasse as três principais, ou seja, aquelas que o mesmo mais exercia no cotidiano da coordenação de curso onde atua. Porém, seis respondentes indicaram mais de três opções, que foram mantidas para não prejudicar a fidedignidade dos dados coligidos.

Nesse contexto, a função organização foi a mais indicada entre os respondentes, com 15 indicações (75\%). Por sua vez, a função planejamento teve 13 menções $(65 \%)$, seguida da liderança com 11 citações (55\%), da função de mediador com 10 respostas (50\%) e da função 


\section{ESTILOS GERENCIAIS DOS COORDENADORES DE CURSOS DE GRADUAÇÃO DE UMA INSTITUIÇÃO DE ENSINO SUPERIOR \\ DOI: https://doi.org/10.5007/1983-4535.2021.e73091}

de solucionador de conflitos que foi indicada por 9 respondentes (45\%). Em sentido oposto, as funções com menos indicações foram a de "controle" (com 4 respostas), as funções de "representante", "negociador" e "alocador de recursos" (todas com 3 indicações), a função de empreendedor (com 2 menções) e a função contato (com somente uma resposta). Em relação às funções mais indicadas (organização, planejamento, liderança e alocador de recursos) os achados desta pesquisa se equiparam aos resultados do estudo de Oliveira et al. (2015), visto terem identificado as referidas funções como as mais citadas também naquele contexto empresarial.

Em relação à organização das atividades, a primeira indagação referiu-se ao envolvimento do respondente na execução das atividades operacionais. Para dezessete respondentes $(85 \%)$ o envolvimento consiste na execução da maioria das atividades operacionais importantes, enquanto que outros três (15\%) envolvem-se mais na supervisão da execução das atividades operacionais.

A segunda questão visava conhecer para qual situação o coordenador dedicava mais tempo no trabalho. Para quinze dos respondentes $(75 \%)$ a dedicação é mais expressiva na realização das atividades rotineiras, para três participantes $(15 \%)$ consistia na busca pela eficiência operacional e administrativa e dois coordenadores (10\%) dedicavam-se à busca pela qualificação e satisfação dos estudantes.

Quando questionados acerca da tomada de decisão sobre o gerenciamento do curso, sete $(35 \%)$ alegaram tomar a maioria das decisões gerenciais. Entretanto, doze mencionaram que as decisões gerenciais são tomadas na maioria das vezes juntamente com os gestores hierarquicamente superiores e somente um respondente asseverou que as decisões gerenciais são tomadas por gestores de instâncias superiores. Essas respostas reforçam os achados de uma das questões do processo de comunicação que indicava autonomia e poder de decisão dos coordenadores.

Em relação ao grau de existência de procedimentos, normas ou regras escritas. Para oito dos respondentes (40\%) o grau é moderado. Contudo, doze dos participantes $(60 \%)$ consideram o grau de existência alto, com estabelecimento de muitas normas e regras escritas. Esses resultados combinam com os achados de outra questão do processo de comunicação que evidenciava que a comunicação com a reitoria ocorre, na maioria das vezes, por escrito.

Indagados sobre o nível de reação dos concorrentes quando a instituição em que atuam inova, seis (30\%) afirmaram ser baixo (ou seja, reagem pouco ou não reagem). Todavia, dez 


\section{ESTILOS GERENCIAIS DOS COORDENADORES DE CURSOS DE GRADUAÇÃO DE UMA \\ INSTITUIÇÃO DE ENSINO SUPERIOR \\ DOI: https://doi.org/10.5007/1983-4535.2021.e73091}

coordenadores $(50 \%)$ avaliam que o grau de reação é moderado, emergindo que algumas vezes percebem reações da concorrência. Contudo, quatro dos respondentes (20\%) avaliam como alto o grau de reação das instituições competidoras, pois consideram que quase sempre reagem.

Também foi investigado sobre a forma de monitoramento e respostas às mudanças provenientes de fatores externos. Acerca disso, observou-se que $30 \%$ dos coordenadores aguardam os acontecimentos para tomar medidas, enquanto que $35 \%$ procuram agir antes dos efeitos de alguns acontecimentos e outros 35\% acompanham os eventos do ambiente e agem preventivamente. As diferentes formas de reações podem indicar que os fatores externos impactam diferentemente nos diversos cursos ofertados pela instituição e que cada coordenador adota uma estratégia de acordo com as suas necessidades e demandas específicas do curso.

Questionou-se, ainda, qual a principal preocupação da instituição na atualidade. Das respostas coligidas concluiu-se que para seis coordenadores $(30 \%)$ a principal preocupação está relacionada com a obtenção de novos alunos. Para oito $(40 \%)$ o foco das atenções está relacionado com a estabilização do negócio (sustentação da base de alunos) e para seis inquiridos (30\%) a preocupação maior consiste na expansão do negócio (ampliação da base de alunos). Então, considerando que os cursos apresentam demandas e cenários díspares entre si, os resultados dessa pergunta podem evidenciar que a instituição pesquisada adota estratégias específicas para cada curso (ou para os cursos que apresentem situação similar) a fim de alcançar as metas estabelecidas.

Por último foi indagado sobre a principal intenção da instituição no momento, sendo que nessa questão permitiu-se que o respondente anotasse mais de uma opção. Constatou-se, então, um alinhamento entre as respostas porque quatorze respondentes $(70 \%)$ escolheram a opção "qualidade acadêmica (Enade)" como o foco primordial atualmente. Ainda, onze coordenadores (55\%) escolheram a "redução de custos (valor das mensalidades)" como uma das principais intenções da instituição; quatro participantes (20\%) apontaram "consolidar-se como Universidade" e apenas um (5\%) indicou priorizar a "captação de alunos". A partir disso, considera-se que há uma sincronia dos cursos em relação às metas e objetivos da IES pesquisada, especialmente no que concerne à preocupação de formar profissionais qualificados. 
Na sequência do estudo foi investigado sobre a abordagem do processo na instituição, ou seja, o que o profissional faz na rotina da coordenação do curso. Nesse rumo, as respostas coletadas estão resumidas na Tabela 2.

Tabela 2: Abordagem do processo

\begin{tabular}{|c|c|c|c|c|c|c|c|}
\hline Itens & MR (\%) & $\mathrm{R}(\%)$ & $\mathrm{O}(\%)$ & NR (\%) & VV $(\%)$ & $\mathrm{F}(\%)$ & MF (\%) \\
\hline $\begin{array}{l}1 \text { - Pensa sobre o futuro da instituição e analisa } \\
\text { as possíveis oportunidades e ameaças. }\end{array}$ & - & 5 & 5 & - & 5 & 65 & 20 \\
\hline $\begin{array}{l}2 \text { - Pensa sobre o futuro do curso e analisa as } \\
\text { possíveis oportunidades e ameaças. }\end{array}$ & - & - & - & - & 10 & 35 & 55 \\
\hline 3 - Pensa em objetivos para a instituição. & - & 10 & 5 & 5 & 30 & 30 & 20 \\
\hline 4 - Pensa em objetivos para o curso. & - & - & - & 5 & 25 & 30 & 40 \\
\hline $\begin{array}{l}5 \text { - Escolhe alternativas para se alcançar os } \\
\text { objetivos da instituição. }\end{array}$ & - & 5 & 5 & 5 & 30 & 40 & 15 \\
\hline $\begin{array}{l}6 \text { - Escolhe alternativas para se alcançar os } \\
\text { objetivos do curso. }\end{array}$ & - & - & 5 & - & 10 & 50 & 35 \\
\hline $\begin{array}{l}7 \text { - Contrata pessoal (professores), define } \\
\text { atribuições e responsabilidades para a execução } \\
\text { das tarefas. }\end{array}$ & 10 & 10 & 15 & 10 & 30 & 15 & 10 \\
\hline $\begin{array}{l}8-\text { Define regras de conduta e de } \\
\text { comportamento dos professores vinculados ao } \\
\text { curso. }\end{array}$ & 5 & 5 & 10 & 5 & 45 & 15 & 15 \\
\hline $\begin{array}{l}9 \text { - Gerencia os bens materiais ou os recursos } \\
\text { financeiros demandados pelo Curso de } \\
\text { Graduação. }\end{array}$ & - & 5 & 10 & 10 & 25 & 15 & 35 \\
\hline $\begin{array}{l}10 \text { - Decide e comunica aos pares (professores) } \\
\text { a execução de planos ou de fluxos de trabalho. } \\
11 \text { - Mantém contato com outras pessoas que }\end{array}$ & - & 5 & 10 & - & 15 & 40 & 30 \\
\hline $\begin{array}{l}\text { não sejam vinculadas ao curso, sejam elas } \\
\text { clientes, fornecedores, consultores ou } \\
\text { prestadores de serviço. }\end{array}$ & - & 20 & 20 & 5 & 15 & 30 & 10 \\
\hline $\begin{array}{l}12 \text { - Avalia a execução das atividad.es de seus } \\
\text { pares (professores vinculados ao curso) }\end{array}$ & - & 5 & - & 5 & 35 & 45 & 10 \\
\hline $\begin{array}{l}13 \text { - Avalia o motivo dos desvios na execução } \\
\text { das atividades de seus pares (professores } \\
\text { vinculados ao Curso). }\end{array}$ & - & 5 & 5 & 5 & 45 & 30 & 10 \\
\hline $\begin{array}{l}14 \text { - Supre com informações as demais áreas da } \\
\text { organização. }\end{array}$ & - & - & 5 & 10 & 25 & 45 & 15 \\
\hline $\begin{array}{l}15 \text { - Dialoga com os demais Cursos de } \\
\text { Graduação da Instituição sobre fatores que } \\
\text { aumentam ou reduzem o número de alunos. }\end{array}$ & - & - & - & 10 & 15 & 60 & 15 \\
\hline
\end{tabular}

Fonte: dados da pesquisa.

Ao serem perguntados se pensam sobre o futuro da instituição (questão 1), 65\% dos participantes afirmaram que fazem-no frequentemente e $20 \%$ responderam que isso ocorre muito frequentemente. Quanto ao curso onde atuam (questão 2), as respostas evidenciam que $55 \%$ dos coordenadores pensam muito frequentemente a respeito e $30 \%$ alegam que pensam frequentemente. 


\section{ESTILOS GERENCIAIS DOS COORDENADORES DE CURSOS DE GRADUAÇÃO DE UMA \\ INSTITUIÇÃO DE ENSINO SUPERIOR \\ DOI: https://doi.org/10.5007/1983-4535.2021.e73091}

$\mathrm{Na}$ questão 3, quando foram indagados se pensam em objetivos para a instituição, apenas $20 \%$ dos participantes afirmam fazer isso muito frequentemente, enquanto que ao serem questionados se pensam em objetivos para os cursos (questão 4) esse número aumenta para $40 \%$, além de que $30 \%$ relataram que fazem isso de forma frequente.

O mesmo ocorre quando perguntados se escolhem alternativas para alcançar os objetivos da instituição (questão 5) e, posteriormente, os objetivos do curso (questão 6). No caso dos objetivos da instituição, apenas $15 \%$ disseram fazê-lo muito frequentemente e $40 \%$ asseveraram que fazem-no frequentemente. Em relação aos objetivos do curso, 35\% afirmaram realizar isso muito frequentemente e 50\% frequentemente. Essas respostas revelam que os coordenadores estão mais preocupados com a gestão dos próprios cursos, mas não deixam de pensar na instituição como um todo.

A questão 7 destacou-se em relação às demais por apresentar maior dispersão entre as respostas. A opção "várias vezes" foi indicada por 30\% dos respondentes e as opções "muito raramente", "raramente", "não realizo" e "muito frequentemente" foram apontadas por 10\% dos respondentes. Ainda, $15 \%$ dos participantes afirmaram fazer "ocasionalmente" e os demais (15\%) disseram fazê-lo de forma "frequente".

Em relação à definição de regras de conduta e de comportamento (questão 8), o maior percentual concentrou-se na opção "várias vezes", com $45 \%$ dos respondentes. Quando questionados sobre o gerenciamento dos bens materiais ou recursos financeiros do curso (questão 9), 35\% afirmaram fazer com muita frequência, 15\% asseveraram fazer frequentemente e $25 \%$ disseram fazer várias vezes. Esses resultados podem indicar que há gestão compartilhada de bens e equipamentos entre cursos e/ou setores da instituição.

A questão 10 indagou se o respondente decide e comunica aos pares a execução de planos ou fluxos de trabalho. Nesse quesito, $40 \%$ dos coordenadores asseguraram fazer isso frequentemente e outros $30 \%$ muito frequentemente. Esses percentuais salientam o compromisso e a preocupação dos gestores com a qualidade dos cursos, conforme evidenciado nas questões anteriores.

No que tange ao contato com pessoas externas aos cursos (questão 11), 30\% dos respondentes mencionaram fazê-lo de forma frequente. Porém, $40 \%$ citaram fazê-lo raramente ou ainda ocasionalmente. Essas respostas podem sugerir que os contatos externos são realizados mais em nível institucional do que diretamente pelos cursos da instituição em tela. 


\section{ESTILOS GERENCIAIS DOS COORDENADORES DE CURSOS DE GRADUAÇÃO DE UMA \\ INSTITUIÇÃO DE ENSINO SUPERIOR \\ DOI: https://doi.org/10.5007/1983-4535.2021.e73091}

No tocante à avaliação de seus pares (questão 12), os achados reafirmam a preocupação dos gestores com a qualidade dos cursos porque $45 \%$ destacaram que avaliamnos de forma frequente, $35 \%$ asseguraram realizar essa avaliação várias vezes e $10 \%$ dos coordenadores alegam que avaliam muito frequentemente. Ainda sobre o desempenho dos professores, os respondentes foram questionados se avaliam os motivos de desvios na execução das atividades do corpo docente (questão 13). Nesse caso, observou-se que $45 \%$ dos participantes asseguraram realizar a avaliação várias vezes e outros $30 \%$ afirmaram fazer frequentemente essa análise.

A questão 14 interrogou sobre o repasse de informações às outras áreas da instituição, sendo que $45 \%$ asseveraram repassar informações dos cursos com frequência. A questão 15 buscou conhecer se os coordenadores dialogam com os demais cursos sobre os fatores que aumentam ou reduzem o número de alunos, onde $60 \%$ dos coordenadores participantes do estudo alegaram dialogar com frequência.

Com fulcro no exposto, de modo geral os resultados revelam coordenadores bastante envolvidos com a gestão dos cursos, sem deixar de pensar em estratégias e objetivos para a instituição. Além disso, mostram-se preocupados com a qualidade dos cursos, mantendo bom nível de comunicação com seus pares, bem como com os demais cursos de graduação da IES.

$\mathrm{Na}$ última parte da pesquisa do estudo os coordenadores foram questionados sobre a abordagem dos papéis que executam na instituição no âmbito da rotina de atividades da coordenação do curso, cujas respostas amealhadas estão evidenciadas na Tabela 3.

Tabela 3: Abordagem dos papéis

\begin{tabular}{|c|c|c|c|c|c|c|c|}
\hline Itens & MR (\%) & $\mathrm{R}(\%)$ & $\mathrm{O}(\%)$ & NR (\%) & VV (\%) & $\mathrm{F}(\%)$ & MF (\%) \\
\hline $\begin{array}{l}1 \text { - Participa de eventos externos, como } \\
\text { cerimônias de concessão de prêmios ou } \\
\text { entidade de classe. }\end{array}$ & 10 & 5 & 30 & - & 15 & 30 & 10 \\
\hline $\begin{array}{l}2 \text { - Atende as pessoas externas, como } \\
\text { parceiros, sindicatos, conselhos, entre outros. }\end{array}$ & 5 & 5 & 20 & - & 20 & 30 & 20 \\
\hline $\begin{array}{l}3 \text { - Comunica ordens e orientações aos seus } \\
\text { pares (professores vinculados ao curso). }\end{array}$ & - & - & - & - & 25 & 45 & 30 \\
\hline $\begin{array}{l}4 \text { - Critica, reconhece e motiva seus pares } \\
\text { (professores vinculados ao curso). }\end{array}$ & - & - & 10 & - & 20 & 50 & 20 \\
\hline $\begin{array}{l}5 \text { - Estabelece relacionamentos profissionais } \\
\text { com pessoas externas à instituição. }\end{array}$ & - & 5 & 5 & - & 15 & 55 & 20 \\
\hline $\begin{array}{l}6 \text { - Repassa informações externas importantes } \\
\text { aos seus pares }\end{array}$ & - & - & 5 & - & 20 & 55 & 20 \\
\hline $\begin{array}{l}7 \text { - Identifica e coleta informações relevantes } \\
\text { para a instituição. }\end{array}$ & - & - & 5 & 5 & 30 & 40 & 20 \\
\hline $\begin{array}{l}8 \text { - Identifica e coleta informações relevantes } \\
\text { para o curso }\end{array}$ & - & - & 5 & 5 & 5 & 50 & נני \\
\hline
\end{tabular}




\begin{tabular}{|c|c|c|c|c|c|c|c|}
\hline Itens & MR (\%) & R (\%) & $\mathrm{O}(\%)$ & NR (\%) & VV (\%) & F (\%) & MF (\%) \\
\hline $\begin{array}{l}9 \text { - Avalia o desempenho da instituição, a fim } \\
\text { de realizar ajustes e mudanças. }\end{array}$ & - & 5 & - & 10 & 45 & 35 & 5 \\
\hline $\begin{array}{l}10 \text { - Avalia o desempenho do curso, a fim de } \\
\text { realizar ajustes e mudanças. }\end{array}$ & - & S & 5 & 5 & 5 & 50 & 35 \\
\hline $\begin{array}{l}11 \text { - Verifica as ações dos competidores e os } \\
\text { acontecimentos do ambiente externo. }\end{array}$ & - & 5 & 5 & 15 & 20 & 35 & 20 \\
\hline $\begin{array}{l}12 \text { - Concede entrevista ou realiza discursos ou } \\
\text { apresenta informações da instituição ou do } \\
\text { Curso para públicos externos. }\end{array}$ & - & 10 & 15 & 10 & 10 & 45 & 10 \\
\hline $\begin{array}{l}13 \text { - Pronuncia-se sobre a história ou a situação } \\
\text { da instituição ou do Curso em eventos ou } \\
\text { reuniões externos. }\end{array}$ & - & - & 15 & 10 & 25 & 40 & 10 \\
\hline $\begin{array}{l}14 \text { - Reivindica benefícios para o Curso ou } \\
\text { para a Instituição como um todo. }\end{array}$ & - & - & 5 & 5 & 15 & 45 & 30 \\
\hline $\begin{array}{l}15 \text { - Identifica oportunidades para explorar } \\
\text { novos negócios para a instituição. }\end{array}$ & - & 5 & 10 & 20 & 15 & 40 & 10 \\
\hline $\begin{array}{l}16 \text { - Procura por inovações que possam se } \\
\text { tornar projetos da instituição. }\end{array}$ & - & - & 25 & 10 & 20 & 30 & 15 \\
\hline $\begin{array}{l}17 \text { - Organiza o tempo para a realização dos } \\
\text { trabalhos. }\end{array}$ & - & - & 5 & 5 & 15 & 60 & 15 \\
\hline $\begin{array}{l}18 \text { - Decide sobre os investimentos da } \\
\text { instituição relacionados ao curso. }\end{array}$ & - & - & 15 & 10 & 25 & 20 & 30 \\
\hline $\begin{array}{l}19 \text { - Distribui os recursos financeiros, } \\
\text { materiais e físicos, a fim de maximizar a } \\
\text { eficiência da instituição. }\end{array}$ & - & - & 20 & 5 & 25 & 10 & 40 \\
\hline $\begin{array}{l}20 \text { - Convence outras pessoas a cooperarem } \\
\text { com projetos da instituição. }\end{array}$ & - & - & 10 & 10 & 40 & 30 & 10 \\
\hline $\begin{array}{l}21 \text { - Negocia acordos com entidades de classe, } \\
\text { governamentais e jurídicas. }\end{array}$ & 25 & - & 25 & 25 & 10 & 10 & 5 \\
\hline
\end{tabular}

Fonte: dados da pesquisa.

Em relação à participação em eventos externos (questão 1), 30\% afirmaram participar ocasionalmente, enquanto que outros $30 \%$ alegaram que as participações em eventos externos ocorrem frequentemente. A questão 2 buscou conhecer acerca do atendimento às pessoas externas à instituição, onde se apurou que $30 \%$ dos coordenadores registraram que isso ocorre frequentemente.

Quando perguntados se comunicam ordens e orientações a seus pares (questão 3), 45\% salientaram fazer com frequência e outros 30\% com muita frequência. A questão 4 visou conhecer a respeito das críticas e motivações direcionadas aos pares, onde $50 \%$ dos respondentes asseguraram criticar, reconhecer ou motivá-los frequentemente, outros 40\% disseram fazer isso muito frequentemente ou várias vezes. Esses resultados indicam haver boa comunicação das coordenações para com os professores envolvidos.

No que se refere aos relacionamentos profissionais com entidades externas (questão 5), $55 \%$ dos participantes asseguraram estabelecer tais relações frequentemente e $20 \%$ 


\section{ESTILOS GERENCIAIS DOS COORDENADORES DE CURSOS DE GRADUAÇÃO DE UMA \\ INSTITUIÇÃO DE ENSINO SUPERIOR \\ DOI: https://doi.org/10.5007/1983-4535.2021.e73091}

afirmaram ocorrer muito frequentemente. Esses resultados reforçam os achados de questão anterior onde grande parte afirmou manter contato com pessoas externas à instituição.

Ao serem interrogados sobre o repasse de informações externas importantes (questão 6), apenas 5\% dos respondentes afirmaram fazê-lo ocasionalmente. Os demais informaram repassar informes várias vezes (20\%), frequentemente (55\%) ou muito frequentemente $(20 \%)$.

Nas questões 7 e 8 se almejou conhecer se os coordenadores identificam e coletam informações para a instituição e para o curso, respectivamente. No que concerne à instituição, $60 \%$ afirmaram que isso ocorre de forma frequente ou muito frequentemente. Quando referese ao curso, os percentuais foram mais expressivos e concentrados, alcançando o nível de $85 \%$.

Na questão 9 foi indagado se os respondentes avaliam o desempenho da instituição a fim de realizar ajustes e mudanças, onde $45 \%$ aduziram que fazem-no várias vezes. $\mathrm{Na}$ questão 10 , ao referir-se à avaliação da performance do curso, constatou-se que $50 \%$ dos gestores indicaram avaliar o desempenho com frequência e outros 35\% avaliam muito frequentemente. Essas respostas confirmam os resultados encontrados anteriormente, nos quais dessumiu-se que há forte preocupação dos coordenadores a respeito do nível de qualidade dos cursos.

Referente às ações dos competidores e ao monitoramento do ambiente externo (questão 11), 35\% dos respondentes verificam as ações dos competidores e os acontecimentos relevantes no ambiente externo com frequência e outros $20 \%$ realizam isso com muita frequência.

A questão 12 investigou sobre a divulgação do curso a públicos externos, onde $45 \%$ asseguraram conceder entrevistas, realizar discursos ou apresentar informações do curso com frequência. Nesse contexto, os respondentes foram interrogados também se pronunciam-se acerca da história ou situação da instituição (ou do curso) em eventos ou reuniões externas (questão 13), onde $40 \%$ asseguraram fazê-lo com frequência e outros $25 \%$ o fazem várias vezes.

Quando inquiridos se reivindicam benefícios para o curso ou para a instituição (questão 14), $75 \%$ dos respondentes asseguraram fazer frequentemente ou muito frequentemente $(45 \%$ e $30 \%$, respectivamente). Em relação à identificação de novas oportunidades (questão 15), 40\% dos respondentes alegaram que identificam oportunidades de novos negócios para a instituição, mas $20 \%$ mencionaram que não fazem isso. Questionou- 
se, ainda, sobre a busca por inovações (questão 16), na qual 30\% aduziram que buscam inovações que se tornem projetos para a instituição frequentemente, enquanto que com $25 \%$ isso ocorre apenas ocasionalmente.

Em relação à questão 17 , cerca de $60 \%$ asseveraram que a organização do tempo para realização dos trabalhos é frequente. Os resultados indicam haver planejamento para a realização das atividades, visto que apenas 5\% dos respondentes admitiram fazê-lo ocasionalmente e outros $5 \%$ que não realizam esse procedimento.

Buscou-se conhecer também sobre os investimentos realizados no curso (questão 18), na qual 30\% manifestaram que decidem sobre os investimentos da instituição em relação ao curso com muita frequência. No que se refere à distribuição de recursos (questão 19), 40\% asseguraram que gerenciam a distribuição destes com muita. Esses resultados corroboram os achados de questões precedentes que também indicaram certa autonomia dos coordenadores na gestão dos cursos.

A questão 20 priorizou conhecer a rotina dos respondentes em relação à busca por parcerias para os projetos da instituição. Apenas $10 \%$ assumiram que não tentam convencer outras pessoas a cooperarem com os projetos da Instituição. Contudo, outros 10\% afirmaram fazer isso de forma ocasional e os demais respondentes afirmaram que executam tal atividade várias vezes, frequentemente ou muito frequentemente (40\%, 30\% e 10\% respectivamente).

A última questão (21) apresentada pretendeu saber sobre as negociações efetuadas pelos respondentes, sendo que as opções "não realizo", "muito raramente" e "ocasionalmente", representam $75 \%$ dos respondentes. Essa realidade sugere que os coordenadores abrangidos no estudo não costumam exercer esse papel.

Os resultados desta parte do questionário se coadunam com alguns dos achados da parte precedente estudo, especialmente quanto ao diálogo com seus pares, quer seja repassando ordens e orientações ou por meio de feedback de suas atividades. Os resultados revelam, também, que há profissionais comprometidos com o curso que coordenam e com a instituição, sendo que estes buscam participar ativamente das decisões gerenciais e do crescimento da instituição por meio da efetivação de projetos e estão atentos à qualidade do curso que dirigem. 


\section{ESTILOS GERENCIAIS DOS COORDENADORES DE CURSOS DE GRADUAÇÃO DE UMA \\ INSTITUIÇÃO DE ENSINO SUPERIOR \\ DOI: https://doi.org/10.5007/1983-4535.2021.e73091}

\subsection{DISCUSSÃO DOS RESULTADOS E COTEJAMENTO COM PESQUISAS PRECEDENTES}

Em relação ao perfil dos respondentes observou-se que os principais achados desta pesquisa assemelham-se aos achados de estudos anteriores com este foco. Nesse sentido, observou-se que $85 \%$ dos respondentes possuem entre 26 e 45 anos, enquanto que a maioria $(60 \%)$ são do sexo feminino. Esses resultados se coadunam, parcialmente, com Machado et al. (2016) quando evidenciaram que a maior parcela dos coordenadores e tutores analisados são do gênero feminino (83,3\%), mas possuíam idades entre 36 e 55 anos $(66,6 \%)$.

Por outro ângulo, Marcon (2011) argumentou que para assumir a coordenação de um curso de graduação o gestor deve estar preparado porque se trata de uma tarefa complexa, que exige combinar aspectos técnicos e políticos e requer habilidades gerenciais que devem ser desenvolvidas e aprendidas. A respeito disso, Franco (2002) assevera que o coordenador de curso deve ser um estudante permanente e buscar aprimoramento constante na sua lide cotidiana. Nesse sentido, concluiu-se que a IES pesquisada conta com um quadro de gestores preparados para a função e engajados em projetos de formação continuada. Essa conclusão está fundamentada no percentual de respondentes (70\%) com experiência na área de gestão há mais de cinco anos, no envolvimento destes (70\%) em projetos de pesquisa e, ainda, no fato de que $80 \%$ afirmaram participar regularmente de cursos de capacitação relacionados à gestão.

No que concerne à titulação, Franco (2002) defende que é fundamental que o coordenador de curso possua título de mestre ou doutor, pois além de atender a indicação do Ministério da Educação (MEC), este será mais capacitado para conduzir docentes com titulação similar. Acerca disso, na instituição estudada constatou-se que este preceito é observado, posto que $90 \%$ dos respondentes possuem titulação de mestres e doutores. Resultado similar também foi identificado por Bonfiglio, Beber e Silva (2014) quando constataram que $79 \%$ dos respondentes possuem formação acadêmica stricto sensu. Portanto, os achados destas duas pesquisas sinalizam que as instituições consideradas nos dois estudos estão observando, em seus processos de contratação, a orientação ministerial a respeito da titulação dos docentes.

Quanto às funções executadas, os respondentes indicaram ocuparem-se mais com organização, planejamento, liderança, mediação e solução de conflitos. Destarte, as referidas funções indicam que os coordenadores da IES pesquisada buscam desenvolver um rol de 


\section{ESTILOS GERENCIAIS DOS COORDENADORES DE CURSOS DE GRADUAÇÃO DE UMA \\ INSTITUIÇÃO DE ENSINO SUPERIOR \\ DOI: https://doi.org/10.5007/1983-4535.2021.e73091}

atividades que se assemelha ao preconizado na literatura. Nessa direção, Franco (2002) sugere que o coordenador deve ser um líder reconhecido na sua área profissional e deve desempenhar o papel de animador dos docentes e alunos. Soares (2013) aduz que um dos papéis do gestor universitário é unir os interesses dos discentes ao projeto pedagógico do curso.

No que tange à organização das atividades na instituição, constatou-se que a maioria (75\%) dos coordenadores envolve-se na execução de grande parte das atividades operacionais, dedicando maior tempo de trabalho na realização das atividades rotineiras. Apurou-se, ainda, que somente $25 \%$ dos respondentes dedicam mais tempo de expediente na busca pela eficiência operacional e administrativa ou na busca pela qualificação e satisfação dos estudantes. Esses resultados corroboram os obtidos por Bonfiglio, Beber e Silva (2014), de vez que evidenciaram que os gestores desempenham as atividades de rotina. Atendendo ao preconizado por Marcon (2011) de que os coordenadores tendem a realizar prioritariamente as demandas imediatas. Contudo, os resultados apurados nesta pesquisa divergem do perfil dos coordenadores de pós-graduação que foi deslindado por Fleck e Pereira (2011), revelando coordenadores com perfis direcionados a administrar tarefas e mais voltados ao resultado atingido.

Em relação às decisões gerenciais relativas ao curso, os resultados indicam autonomia e poder de decisão dos coordenadores, visto que apenas um dos respondentes informou que as decisões gerenciais são tomadas por gestores de instâncias superiores. Os demais afirmaram tomar a maioria das decisões ou ainda participar das decisões juntamente com outros gestores. Isso está alinhado com o recomendado por Franco (2002), o qual salienta que o coordenador deve participar efetivamente e ser o motivador da gestão de seu curso.

Outro resultado do estudo consistiu na identificação de que os coordenadores estão mais preocupados com a gestão dos próprios cursos, mas participam e pensam estratégias de gestão para a instituição como um todo. Sobre o tema, Marcon (2011) destaca que o ambiente competitivo não permite improvisações ou dúvidas na gestão de um curso e da instituição. Portanto, é fundamental que a instituição tenha planejamento e propague-o aos seus gestores para que as atividades sejam desenvolvidas com foco nos objetivos da instituição. Nesse sentido, os achados apontam para um alinhamento da compreensão dos coordenadores de cursos em relação às metas e objetivos da IES porque ao serem questionados acerca da principal intenção da instituição no momento, a maioria (70\%) dos respondentes informou 
que o foco atual da instituição é a qualidade acadêmica mensurada pela performance no Enade.

Acerca da comunicação, os resultados do estudo indicam que há boa comunicação na instituição dos coordenadores com seus pares, pois restou evidenciado que esta ocorre de forma frequente ou muito frequente. Nessa direção, os respondentes afirmaram que comunicam seus pares a respeito da execução de planos ou fluxos de trabalho, repassam informações importantes (tanto de âmbito externo como interno) e informam sobre críticas e menções elogiosas em relação ao trabalho desenvolvido.

Por último, Bonfiglio, Beber e Silva (2014) constataram que a qualificação inerente ao cargo e a atuação participativa aliada à missão, objetivos e metas da instituição foram fatores essenciais para o padrão de qualidade e as competências dos gestores encontrados nas IES que pesquisaram. Sobre isso, contexto assemelhado também foi observado na IES estudada, onde ficou evidente que os coordenadores estão bastante envolvidos com a gestão dos cursos, preocupados com a qualidade destes e mantêm bom nível de comunicação com seus pares e demais cursos de graduação da universidade. Além disso, buscam melhorar a qualidade dos cursos por meio de avaliações constantes e pela busca por novas oportunidades e projetos.

\section{CONCLUSÕES}

Este estudo pretendeu obter resposta acerca dos estilos gerenciais dos coordenadores de curso de graduação de uma instituição de ensino superior. Para tanto, objetivou identificar os estilos gerenciais dos coordenadores de curso de graduação de uma instituição de ensino superior comunitária sediada em Santa Catarina. Nesse sentido, os autores consideram que tal pergunta foi adequadamente respondida e o objetivo alcançado de forma satisfatória, conforme evidenciado nas seções precedentes.

Quanto aos resultados mais relevantes é importante salientar alguns aspectos. Em relação ao perfil dos respondentes constatou-se que os coordenadores de cursos são relativamente jovens, visto que a maioria (85\%) dos participantes da pesquisa tem menos de 45 anos. Identificou-se que a maior parte já possuía experiência anterior em gestão, mesmo que para alguns destes essa possa ser a primeira experiência na área universitária. Constatouse considerável envolvimento dos respondentes com pesquisa, o que comprova alinhamento aos conceitos e práticas de uma universidade. Em relação à titulação dos respondentes concluiu-se que está adequada à função desempenhada. 


\section{ESTILOS GERENCIAIS DOS COORDENADORES DE CURSOS DE GRADUAÇÃO DE UMA \\ INSTITUIÇÃO DE ENSINO SUPERIOR \\ DOI: https://doi.org/10.5007/1983-4535.2021.e73091}

No que concerne ao processo de comunicação e planejamento estratégico, quanto à forma de comunicação esta é prioritariamente executada de maneira formal, pois a maioria das comunicações acontece por escrito. Acerca do processo de tomada de decisão, todos indicaram consultar outras instâncias da IES para decisões importantes. Quanto ao planejamento estratégico, a maioria conhece o processo de elaboração e as prioridades deste, visto que $89,5 \%$ consideram que são priorizados em sua elaboração os objetivos e metas da instituição.

Por outro lado, o estudo buscou conhecer as principais ocupações dos coordenadores na instituição em termos das funções e papéis que cabem ao administrador. Nesse contexto, as funções mais exercidas referem-se à "organização", com 15 indicações (75\%); ao "planejamento", com 13 menções (65\%); à "liderança", com 11 respostas (55\%) e à de "mediador", com 10 citações (50\%). Esses achados se equiparam aos resultados do estudo de Oliveira et al. (2015), que fundamentou o questionário aplicado nesta pesquisa.

Em relação à organização das atividades na instituição, restou evidenciado que a IES em tela possui gestores com grande envolvimento na execução das atividades operacionais importantes, mas com dedicação maior às atividades rotineiras. As respostas evidenciaram, também, que os gestores possuem certo grau de autonomia e poder de decisão, pois estes participam ativamente das decisões gerenciais relativas aos cursos que coordenam.

Quanto à abordagem do processo, foi possível identificar que os coordenadores participantes da pesquisa estão mais preocupados com a gestão dos próprios cursos, mas não deixam de pensar na instituição como um todo. Essa constatação pode ser observada pelas concentrações das respostas das 15 questões desse tópico, onde os maiores percentuais de respostas concentraram-se nas opções "várias vezes", "frequentemente" e "muito frequente". Também foi possível dessumir que os coordenadores mostraram-se preocupados com a qualidade dos cursos, mantendo bom nível de comunicação com seus pares e com os demais cursos de graduação da instituição.

$\mathrm{Na}$ última parte do estudo, que referia-se à abordagem dos papéis, restaram consolidados alguns dos achados do estudo como a frequente comunicação e diálogo com os pares, o comprometimento dos coordenadores com os cursos e com a própria instituição e a participação efetiva nas decisões gerenciais do curso. À semelhança do citado no parágrafo precedente, os percentuais mais relevantes de respostas das 21 questões abordadas nesta seção 
ficaram também nos níveis de maior frequência (várias vezes, frequentemente e muito frequentemente).

No que tange à principal contribuição do estudo, considera-se que esta reside no fato de ter propiciado um diagnóstico sobre a situação de uma instituição universitária em termos do perfil dos gestores de cursos, especialmente em termos da abordagem dos processos que participam e dos papéis que exercem. Convém salientar que, embora o estudo tenha sido aplicado a uma instituição específica, os dados apresentam-se relevantes pois são apresentados em profundidade e evidenciam abordagem que se distingue de estudos anteriores no âmbito universitário, visto que havia sido aplicada com essa ênfase somente em empresas de pequeno porte do setor metal-mecânico. Todavia, cabe salientar esse tipo de pesquisa pode ser replicada em outras entidades, independentemente do setor de atuação.

\section{REFERÊNCIAS}

BAYARYSTANOVA, E; ARENOVA, A; NURMUHAMETOVA, R. Education System Management and Professional Competence of Managers. Procedia-Social and Behavioral Sciences, v. 140, p. 427-431, 2014.

BARBOSA, M. A. C; MENDONÇA, J. R. C. O professor-gestor e as políticas institucionais para formação de professores de ensino superior para a gestão universitária. Revista Economia \& Gestão, v. 16, n. 42, p. 61-88, 2016.

BONFIGLIO, S. U; BEBER, B; DA SILVA, E. Gestão acadêmica: uma investigação com instituições de ensino superior do Vale do Itajaí-Santa Catarina. Revista da UNIFEBE, v. 1, n. 13, p. 1-17, 2014.

BRITO, M. R. F. O SINAES e o ENADE: da concepção à implantação. Avaliação: Revista da Avaliação da Educação Superior (Campinas), v. 13, n.3, p. 841-850, 2008.

CUNHA, L. A. Reforma universitária em crise: gestão, estrutura e território. In: TRINDADE, H. (Org.). Universidade em ruínas: na república dos professores. Porto Alegre: CIPEDES, 1999. p. 125-148.

EBERLE, V; COLAUTO, R. D. Pressões institucionais e adoção do Balanced Scorecard: O caso de uma organização do setor elétrico do sul do Brasil. Contabilidade Vista \& Revista, v. 25 , n. 3, p. 95-120, 2015.

FLECK, C. F; PEREIRA, B. A. D. Professores e Gestores: análise do perfil das Competências Gerenciais dos coordenadores de pós-graduação das Instituições Federais de Ensino Superior (IFES) do RS. Organizações \& Sociedade, v. 18, n. 57, 2011. 
FRANCO, E. R. P. de S. Funções do coordenador de curso: como "construir" o coordenador ideal. Brasília: Associação Brasileira de Mantenedoras de Ensino Superior, Caderno 8, 2002.

GIL, A. C. Como elaborar projetos de pesquisa. 5. ed. São Paulo: Atlas, 2010.

MACHADO, M. R; SILVA, J. E. O; PACHECO, A. S. V; MELO, P. A. de. Perfil de tutores e coordenadores de cursos EAD da Universidade Federal de Santa Catarina. Semina: Ciências Sociais e Humanas, v. 37, n. 1, p. 39-52, 2016.

MARCON, S. R. A. Atribuições dos cargos de coordenação e subcoordenação de cursos de graduação. In: XI Congresso Internacional de Gestão Universitária na América do Sul, 7, 2011, Florianópolis. Anais... Florianópolis, 2011.

MIRANDA, A. R. A. Um estudo sobre a dinâmica identitária de professoras gerentes de uma universidade pública. 2010. 162 f. Dissertação (Mestrado em Administração) Universidade Federal de Lavras. Lavras, Minas Gerais, 2010.

OLIVEIRA, J. de.; ESCRIVÃO FILHO, E.; NAGANO, M. S.; FERRAUDO, A. S. . Estilos gerenciais dos dirigentes de pequenas empresas: estudo baseado no ciclo de vida organizacional e nos conceitos de funções e papéis do administrador. Revista Brasileira de Gestão de Negócios, v. 17, n. 57, p. 1279-1299, 2015.

RAUPP, F. M.; BEUREN, I.M. Metodologia da pesquisa aplicável às ciências sociais. IN: BEUREN, I. M. (Org.). Como elaborar trabalhos monográficos em contabilidade: teoria e prática. 3. ed. São Paulo: Atlas, 2003. p. 76-97.

ROESCH, S. M. A. Projetos de estágio e de pesquisa em administração: guia para estágios, trabalhos de conclusão, dissertações e estudos de caso. 3. ed. São Paulo: São Paulo, Atlas, 2006.

SANTOS, L. dos; BRONNEMANN, M. R. Desafios da gestão em instituições de ensino superior: um estudo de caso a partir da percepção de diretores de centro de uma IES pública do sul do Brasil. Revista Gestão Universitária na América Latina - GUAL, v. 6, n. 1, p. 01-21, 2013.

SILVA, A. B.; COSTA, F. J. Itinerários para o desenvolvimento da competência docente na pós-graduação Stricto Sensu em Administração. Revista Economia \& Gestão, v. 14, n. 34, p. 35-57, 2014.

SILVEIRA-MARTINS, E.; CASTRO JÚNIOR, D. F. L. de; MIURA, M. N.; DELUCA, M. A. M.; PEREIRA, M. F. Orientação estratégica como fonte de desempenho acadêmico: a análise de uma IFES. Revista Gestão Universitária na América Latina-GUAL, v. 10, n. 1, p. 1-16, 2017.

SOARES, L. H. Gestão de Instituições de Ensino: o ensino superior privado e os novos parâmetros de perenidade. Universitas: Gestão e TI, v. 3, n. 2, p. 79-87, 2013.

ZANIN, A. et al. Definição de painel de indicadores de desempenho para instituições comunitárias de ensino superior. Revista Gestão Universitária na América LatinaGUAL, v. 8, n. 2, p. 1-27, 2015. 